\title{
VARIABILIDADE DE PRODUÇÃO DE AFLATOXINAS POR LINHAGENS DE Aspergillus flavus EM DIFERENTES TEMPOS DE MANUTENÇÃO'
}

\author{
M.II. TANIWAKI \\ Seção de Microbiologia do Instiuto de Tecnologia de Alimentos - CEP: 13073-000 - Campinas,SP. \\ II. FONSECA
}

Prof. Titular do Dep. de Ciência e Tecnologia Agroindustrial da ESALQ/USP - Caixa Postal 9 - CEP: 13418-900Piracicaba,SP.

A.A. PIZZIRANI-KLEINER

Prof. do Dep. de Genética da ESALQ/USP - Caixa Postal 9 - CEP: 13418-900-Piracicaba,SP.

RESUMO: O presente trabalıo foi realizado com a finalidade de se estudar a produção de aflatoxinas por linhagens de $A$. flavus, recém isoladas, em diferentes tempos de manutenção, a fim de contribuir para um melhor entendimento do mecanismo de variação na produção de aflatoxinas. Para isso, foram utilizadas três linhagens de $A$. Jlavus produtoras de aflatoxinas, classificadas como: a) grande produtora; b) média produtora e c) baixa produtora. Neste experimento, que se estendeu por $\mathbf{2 8 0}$ dias, os fungos foram estudados em dois métodos de preservação: mantido em óleo mineral, no meio Czapeck, e repicado periodicamente em meio Czapeck modificado. A análise da produção de aflatoxinas foi efetuada de $30 \mathrm{em} 30$ dias. A quantificaçāo da toxina foi feita por cromatografia em camada delgada, pela técnica de avaliação visual,de diluição até extinção. Foi constatada uma variaçãona produção de toxina em todas as linhagens, contudo elas ñ̃o perderam suas características originais.

Descritores: Aflatoxinas, Aspergillus flavus, tempo de manutenção.

\section{AFI,ATOXIN PRODUCTION VARIABILITY BY Aspergillus flavus STRAINS AFTER DIFFERENT STORAGE TIMES}

\begin{abstract}
Aflatoxin production by strains recently isolated of Aspergillus flavus was studied, after different storage times understand the mechanisms of possible variations in aflatoxin production. Three $A$. Javus aflatoxin producing strains were utilized, classified as: a) high producer; b) medium producer and c) low producer. The experiment lasted 280 days and the moulds were studied by two preservation methods: oil covered slants on Czapeck's medium and periodic transfer on Czapeck's modified medium. Quantification of the aflatoxin produced was made at $\mathbf{3 0}$ day intervals, on thin-layer chromatography and visual determination by the dilution-to-extinction technique. The production of aflatoxin by all strains varied but they did not lose their initial characteristics. Microscopic examinations revealed thickened zones and hifal enlargements over some globous structures that may be related to aflatoxin production sites.
\end{abstract}

Key Words: Aflatoxins, Aspergillus Javus, storage time.

\section{INTRODUÇÃO}

Aflatoxinas são metabólitos secundários do Aspergillıs flavus, responsáveis por intoxicaçōes e têm se mostrado cancerígenas a diversas cspécics de animais (BUTLER, 1974 e WOGAN, 1966). Devido a essa característica, o estudo das aflatoxinas tem sido alvo de atenção nunca devotada a nenhum outro problema relacionado a fungos (CHRISTENSEN, 1975). Uma série de aflatoxinas são produzidas por $A$. flavus e linhagens relacionadas, destacando-se $B_{1}$ e $B_{2}, G_{1}$ e $G_{2}$, que apresentam fluorescência azul violcta e esverdeada, respectivamente, quando analisadas por cromatografia em camada delgada e utilizando luz ultravioleta em $365 \mathrm{~nm}$ e estão entre as micotoxinas mais potentes.

Vários gêneros e espécies de fungos já foram relatados como produtores de aflatoxinas, porém, atualmente, pode-se dizer que os grandes produtores pertencem às espécies $A$. flavus $\mathrm{e}$ Aspergillis parasiticus, ambas pertencentes ao grupo-cspécie $A$. flavis (RAPER; FENNEL, 1965). Existem linhagens de $A$. flavus que não produzem

\footnotetext{
${ }^{1}$ Parte da dissertação de Mestrado apresentada à ESALQ, pelo primeiro autor.
} 
aflatoxinas, outras que só produzem as do grupo B e outras que só produzem as do grupo G. LIN (1980), revisando vários autores, observou que embora todas as linhagens de $A$. parasiticus sejam produtoras de aflatoxinas, nem todas as de $A$. flavus são capazes de produzir. Além disso, $A$. parasiticus é geralmente maior produtor de aflatoxina do que $A$. flavus e parece que todas as linhagens de $A$. parasiticus conhecidas são produtoras das quatro aflatoxinas $\left(B_{1}, B_{2}, G_{1}\right.$ e $\left.G_{2}\right)$, enquanto que as linhagens de $A$. flavus, na maioria das vezes, produzem somente duas aflatoxinas $B_{1}$ e $B_{2}$. Dados estatísticos de seis países diferentes revelaram que, de 1390 isolados, $60 \%$ dos isolados de A. flavıs eram toxigênicos (DIENER; DAVIS, 1980 e MOREAU, 1974). FONSECA et al. (1974), também chegaram a números semelhantes.

Alguns autores têm tentado distinguir um isolado toxigênico de um não toxigênico, com base em seus caracteres morfológicos e citológicos, como a presença de blastoconídios (BHATNAGAR et al., 1982), clamidoconídios (ABOU-GABAL; FAGERLAND, 1981) e esclerócios (MURAKAMI et al., 1966; TORRES ct al., 1980; WICKLOW; SHOTWELL, 1982), o que indicaria que a linhagem é produtora de aflatoxina. Contudo, MOREAU (1979) adverte a este tipo de associação pelo fato de uma linhagem toxigênica vir a perder sua habilidade de produzir aflatoxina, após subculturas sucessivas em meios sintéticos, ou em alguns casos aumentar sua toxigenicidade por meio de subculturas sucessivas num substrato natural apropriado. Além disso mutantes naturais ou artificiais podem ocorrer, eventualmente.

Inúmeras pesquisas tem demonstrado que há considerável variação na capacidade para produzir aflatoxinas pelas diversas linhagens do grupo A. flavus, mesmo quando são isoladas da mesma fonte (LEAICH; PAPA, 1974; MOREAU, 1979). A produção de aflatoxinas também varia quantitativamente de cultura para cultura, e isolados toxigênicos crescidos no mesmo substrato, e sob as mesmas condições, podem produzir aflatoxinas variando de 100 a $2000 \mu \mathrm{g} / \mathrm{g} \mathrm{dc}$ substrato (HESSELTINE et al., 1966; MURAKAMI et al., 1966). Um dos maiores problemas encontrados pelos pesquisadores no estudo de produção de aflatoxinas é a variação do nível de produção que uma determinada linhagem apresenta durante todo o experimento. Uma linhagem pode ser altamente toxigênica e posteriormente, perder esta alta toxigenicidade. FONSECA ${ }^{1}$, verificou que linhagens de $A$. flavus, altamente produtoras de aflatoxinas em meio sintético (ca. $400 \mu \mathrm{g} / \mathrm{g}$ de micélio), provenientes de trabalho efetuado cerca de 5 anos antes, ao serem utilizadas para produção de aflatoxinas em farelo de amendoim e em milho, tinham perdido quase completamente sua capacidade de produção que não foi alćm de 70-100 ng/g. Não se sabe se esta perda foi devida a fatores externos, como as condições e tempo de manutenção ou se há outros fatores envolvidos.

Por estes motivos, decidiu-se desenvolver o presente trabalho com o objetivo de determinar a produção de aflatoxina pelo Aspergillıs flavıs, após manutenção por diferentes períodos (repetibilidade de produção de aflatoxinas) em comparação com isolados repicados periodicamente, bem como verificar se há alguma relação dos caracteres morfológicos com a produção de aflatoxinas.

\section{MATERIAL E MÉTODOS}

Isolamento e identificação das linhagens de $A$. flavus: As linhagens de $A$. flavus, isoladas a partir de amostras contaminadas de amendoim, foram identificadas através de técnicas micológicas usuais (RAPER; FENNELL, 1965). Oito colônias do grupo A. flavus foram isoladas do amendoim. Cada colônia reccbeu uma numeração, à medida em que foi isolada. Após cada isolado ser testado quanto à produção de aflatoxinas, três linhagens identificadas pelos números 2, 4 e 6 foram escolhidas para este experimento.

Produção de aflatoxinas em meio de cultura: as linhagens de $A$. flavus, mantidas em ágar Czapeck, foram inoculadas em garrafas de Roux, contendo meio YES (DAVIS; DIENER, 1966) e mantidas a $28^{\circ} \mathrm{C}$ durante 10 dias.

Extração de aflatoxinas do meio de cultura: após o período de incubação, as aflatoxinas foram extraídas do meio de cultura $\mathrm{e}$ do micélio fúngico, seguindo-se a técnica descrita por FONSECA et al. (1974).

${ }^{1}$ FONSECA, H., 1980. Dep. Ciência e Tecnologia Agroindustrial da ESALQ/USP, Piracicaba,SP. Comunicaşão Pessoal. 
Identificação e quantificação das aflatoxinas: os extratos foram submetidos à cromatografia de camada delgada, em placas de silicagel-G de 500 $\mu \mathrm{m}$ de espessura. Os cromatogramas foram efetuados em tolueno: acetato de etila: ácido fórmico 90\% (6:3:1 v/v/v) (SCOTT et al., 1970). A leitura das placas foi feita sob luz ultravioleta de ondas longas $(365 \mathrm{~nm})$, de uma lâmpada Philips, tipo HPW, 125 watt, numa câmara escura. A quantificação das aflatoxinas seguiu a técnica de COOMES; FEUELL (1965), que consiste numa avaliação visual de diluição até extinção.

Métodos para a conservação de culturas: as culturas foram mantidas em dois métodos de preservação (FENNELL, 1960): a) Método de preservação sob óleo mineral - as culturas foram mantidas em tubos contendo meio Czapeck (DIFCO), à temperatura de $28^{\circ} \mathrm{C}$. Após a cultura atingir toda a extensão do meio, foi coberta com óleo mineral esterilizado e o frasco foi tampado com uma tampa de borracha. As culturas foram conservadas à temperatura ambiente $\mathrm{c}$, no momento do uso, foram repicadas em meio de C7apcck modificado (FONSECA et al., 1974), antes de serem testadas; b) Método de transferência periódica - as linhagens foram repicadas periodicamente num período médio de 10 dias. $O$ meio utilizado foi Czapeck modificado $e$ as linhagens foram mantidas à temperatura de $28^{\circ} \mathrm{C}$.

Meio de Czapeck modificado: sacarose $=200 \mathrm{~g}$; $\mathrm{NaNO}_{3}=3 \mathrm{~g} ; \mathrm{K}_{2} \mathrm{HPO}_{4}=1 \mathrm{~g} ; \mathrm{MgSO}_{4} .7 \mathrm{H}_{2} \mathrm{O}=$ $0,5 \mathrm{~g} ; \mathrm{KCl}=0,5 \mathrm{~g} ; \mathrm{FeSO}_{4} \cdot 7 \mathrm{H}_{2} \mathrm{O}=0,01 \mathrm{~g}$; extrato de levedura $=7,0 \mathrm{~g}$; ágar $=15,0 \mathrm{~g}$; água destilada $=1000 \mathrm{~mL}$.

Análises microscópicas: as observações microscópicas dos fungos foram realizadas pela técnica do cultivo em lâmina: em placas contendo meio de Czapeck modificado sólido, colocou-se uma lamínula estcrilizada. O fungo foi inoculado ao redor da lamínula, a uma distância de aproximada de $1 \mathrm{~mm}$. Este procedimento foi feito para cada linhagem. Após 24 horas de incubação, o micélio se desenvolveu crescendo sobre a laminula. Esta foi retirada e colocada sobre a lâmina com uma gota do corante safranina alcoólica e, em seguida, foi levada ao microscópio óptico. As estruturas das hifas, conídios $\mathrm{c}$ aparelho conidial foram observadas. $O$ corante safranina alcoólica $0,1 \%$ foi preparado da seguinte forma: Safranina $=1,0 \mathrm{~g}$; álcool $95^{\circ} \mathrm{GL}=100 \mathrm{ml}$.
Foram tomados $10 \mathrm{ml}$ desta solução e completado o volume a $100 \mathrm{ml}$ com água destilada.

\section{RESULTADOS}

Produção inicial de aflatoxinas: a TABELA 1 apresenta a produção inicial de aflatoxinas das três linhagens selecionadas com suas respectivas numerações.

Como mostra a TABELA 1 , as linhagens 4 e 6 produziram aflatoxinas do tipo $B$ e $G$, enquanto a linhagem 2 só produziu aflatoxina do tipo $B$; as aflatoxinas dos tipo $B_{2}$ e $G_{2}$ também foram produzidas, mas não foram determinadas quantitativamente. Todas as linhagens produziram aflatoxinas no meio de cultura e no micélio.

Produção de aflatoxinas pelas linhagens mantidas sob 6leo mineral: neste experimento, que durou 280 dias, a produção de aflatoxinas foi determinada nos seguintes intervalos de tempo: 15 , $30,60,90,120,150,180$ e 280 dias. A TABELA 2 apresenta a produção de a flatoxinas das linhagens 2, 4 e 6, mantidas sob ólco mineral, durante este período.

Conforme a TABELA 2, pode-se observar que não houve uma produção uniforme de aflatoxinas durante os periodos estudados, antes, ela variou grandemente. Não houve também redução na produção de aflatoxinas, com a manutenção de 280 dias, sob óleo mineral. A linhagem 2 (Figura 1) continuou produzindo pouca aflatoxina, na ordem de 0,8 a $6,0 \mu \mathrm{g} / \mathrm{L}$ de $B_{1} \mathrm{em}$ meio de cultura, e de 0,3 a $8,8 \mu \mathrm{g} / \mathrm{kg}$ de $B_{1}$ no micélio; a linhagem 4 (Figura 2) produziu de 20 a $120 \mu \mathrm{g} / \mathrm{L}$ de $B_{1}$ e de 60 a $120 \mu \mathrm{g} / \mathrm{L}$ de $G_{1} \mathrm{em}$ meio de cultura, e de 27,3 a $209 \mu \mathrm{g} / \mathrm{kg}$ de $B_{1}$ e de 35 a $180 \mu \mathrm{g} / \mathrm{kg}$ de $G_{1}$ no micćlio; a linhagem 6 (Figura 3) produziu de 40 a $200 \mu \mathrm{g} / \mathrm{L}$ de $\mathrm{B}_{1}$ e de 120 a 480 $\mu \mathrm{g} / \mathrm{L}$ de $G_{1} \mathrm{~cm}$ meio de cultura, e no micélio a produção foi de 61 a $291 \mu \mathrm{g} / \mathrm{kg}$ de $B_{1}$ e de 173 a $364 \mu \mathrm{g} / \mathrm{kg}$ de $\mathrm{G}_{1}$. As aflatoxinas continuaram sendo produzidas, tanto no meio de cultura como no micélio e as linhagens que produziam aflatoxinas do tipo $\mathrm{B}$ e $\mathrm{G}$ continuaram produzindo. A linhagem 2 , em nenhum momento deste experimento, produziu aflatoxina do tipo G. No geral, a aflatoxina $G_{1}$ foi produzida em maior quantidade que a $B_{1}$ pelas linhagens 4 e 6 .

Produção de aflatoxinas pelas linhagens repicadas periodicamente: paralelamente ao estudo das linhagens mantidas em óleo mineral, 
foram realizadas, da mesma forma, análises das linhagens repicadas periodicamente. A TABELA 3 apresenta estes dados.

Como mostra a TABELA 3, novamente não houve uniformidade na produção de aflatoxinas durante os períodos estudados. Cada linhagem continuou produzindo aflatoxina no meio de cultura e no micélio, sem perder as características de produção das culturas iniciais. Embora, em algumas épocas, a produção de aflatoxinas tenha diminuído em mais de $50 \%$, quando comparadas à produção inicial, em outras épocas a produção aumentou mais de $100 \%$. A produção de aflatoxina na linhagem 2 (Figura 4) variou de 0,4 a $10,0 \mu \mathrm{g} / \mathrm{L}$ de $B_{1}$ em meio de cultura, e de 0,8 a $12,0 \mu \mathrm{g} / \mathrm{kg}$ no micélio; na linhagem 4 (Figura 5), de 20 a 80 $\mu \mathrm{g} / \mathrm{L}$ de $B_{1}$ e de 45 a $180 \mu \mathrm{g} / \mathrm{L}$ de $G_{1}$ em meio de cultura, e de 21,7 a $142 \mu \mathrm{g} / \mathrm{kg}$ de $B_{1}$ e de 49 a 214 $\mu \mathrm{g} / \mathrm{kg}$ de $G_{1}$ no micélio; e na linhagem 6 (Figura 6), de 30 a $140 \mu \mathrm{g} / \mathrm{L}$ de $B_{1}$ e de 80 a $240 \mu \mathrm{g} / \mathrm{L}$ de $G_{1}$ em meio de cultura, e no micélio a produção foi de 30,7 a $212 \mu \mathrm{g} / \mathrm{kg}$ de $\mathrm{B}_{1}$ e de 46,2 a $318 \mu \mathrm{g} / \mathrm{kg}$ de $G_{1}$.

Não se pôde notar diferença entre as culturas mantidas sob ólco mineral e as culturas repicadas periodicamente, com relação à produção de aflatoxinas. A média foi tomada de duas repetições, mas houve diferença em algumas repetições, mesmo sendo trabalhadas em condições similares.

Análise dos caracteres morfologicos das linhagens: estas linhagens diferiram morfologicamente quanto à coloração de suas colônias, produção dos conídios e conidióforos. Quando elas foram testadas quanto à produção de conídios no meio Czapeck modificado e no amendoim autoclavado, as linhagens 2 e 4 produziram os conídios abundantemente, tanto no meio de cultura como no amendoim. A linhagem 6 por sua vez, produziu poucos conídios em ambos os substratos e houve ocasiões em que seu crescimento foi predominantemente micelial. Contudo, a produção de aflatoxinas não diminuiu significativamente e não foi notada relação alguma entre produção de aflatoxinas e conidiação, uma vez que a produção de aflatoxinas ocorreu nas duas formas.

Analisando as linhagens microscopicamente, verificou-se que a linhagem 6 apresentou poucos conidioforos $\mathbf{e}$ a linhagem 2 apresentou um número maior, quando comparada com as outras. Observou-se tamberm, em todas as linhagens, uma região de alargamento de hifas com paredes espessas e presença de algumas estruturas globosas. Nessa região, quase não se verificou a presença de conidioforos.

Contudo, o estudo destas estruturas não foi aprofundado neste trabalho.

\section{DISCUSSÃo}

Ao compararmos os dados de produção de aflatoxinas, das linhagens mantidas em b́leo mineral (TABELA 2) com os dados das linhagens repicadas periodicamente (TABELA 3), podemos observar que ambos se comportaram de forma semclhante. A produção de aflatoxinas, nas três linhagens, durante cada época do experimento, não se manteve uniforme, embora cada linhagem não tenha perdido a característica original, isto $\hat{\epsilon}$, a linhagem 2 continuou produzindo pouca aflatoxina, enquanto as outras duas linhagens continuaram produzindo maiores quantidades. De acordo com FENNELL (1960), estas variações ocorrem durante as transferências de inóculo, de um frasco para outro e quando este é oriundo de áreas envelhecidas: o acúmulo do produto do metabolismo pode exercer influência mutagênica.

Muitos estudos têm sido realizados com o fim de se descobrir métodos para manutenção de fungos por longos periodos, contudo a maioria das técnicas tem procurado estender a longevidade das culturas, procurando manter as características fisiológicas como: patogenicidade, produção de substâncias de interesses comerciais (antibióticos, enzimas, etc) e, neste caso, a produção de aflatoxinas.

As linhagens mantidas sob óleo mineral foram menos trabalhadas do que as repicadas periodicamente, contudo, a variação ocorreu em ambas. De acordo com MOREAU (1979), a produção de aflatoxina é, geralmente, proporcional ao peso do micélio formado na cultura, sendo um máximo produzido quando a biomassa atinge o seu valor ótimo e declina rapidamente no momento em que o micélio inicia a sua autólise. Neste experimento, embora a área do inóculo escolhida tenha sido sempre a do crescimento da colônia, o número de conídios viáveis não foi uniforme. Portanto, a variação ocorreu, provavelmente, devido ao inóculo, que nem sempre produziu a mesma quantidade de micélio e, conseqüentemente, de aflatoxinas. KARUNARATNE; BULLERMAN (1990) também verificaram que a produção de aflatoxinas por $A$. flavus é diretamente 
TABELA 1 - Produção inicial de aflatoxinas pelas linhagens do grupo A. flavus, isoladas do amendoim (Média de duas repetições).

\begin{tabular}{|c|c|c|c|c|}
\hline \multirow{3}{*}{$\begin{array}{c}\text { Linhagem } \\
\text { No }^{\circ}\end{array}$} & \multicolumn{4}{|c|}{ Produção de Aflatoxinas } \\
\hline & \multicolumn{2}{|c|}{ Meio de Cultura $(\mu \mathrm{g} / \mathrm{l})$} & \multicolumn{2}{|c|}{ Micélio $(\mu \mathrm{g} / \mathrm{kg})$} \\
\hline & $B_{1}$ & $G_{1}$ & $\mathrm{~B}_{1}$ & $G_{1}$ \\
\hline 2 & 4,0 & ND & 8,0 & ND \\
\hline 4 & 40,0 & 120,0 & 72,5 & 108,0 \\
\hline 6 & 80,0 & 120,0 & 104,0 & 156,0 \\
\hline
\end{tabular}

ND $=$ Não delectada.

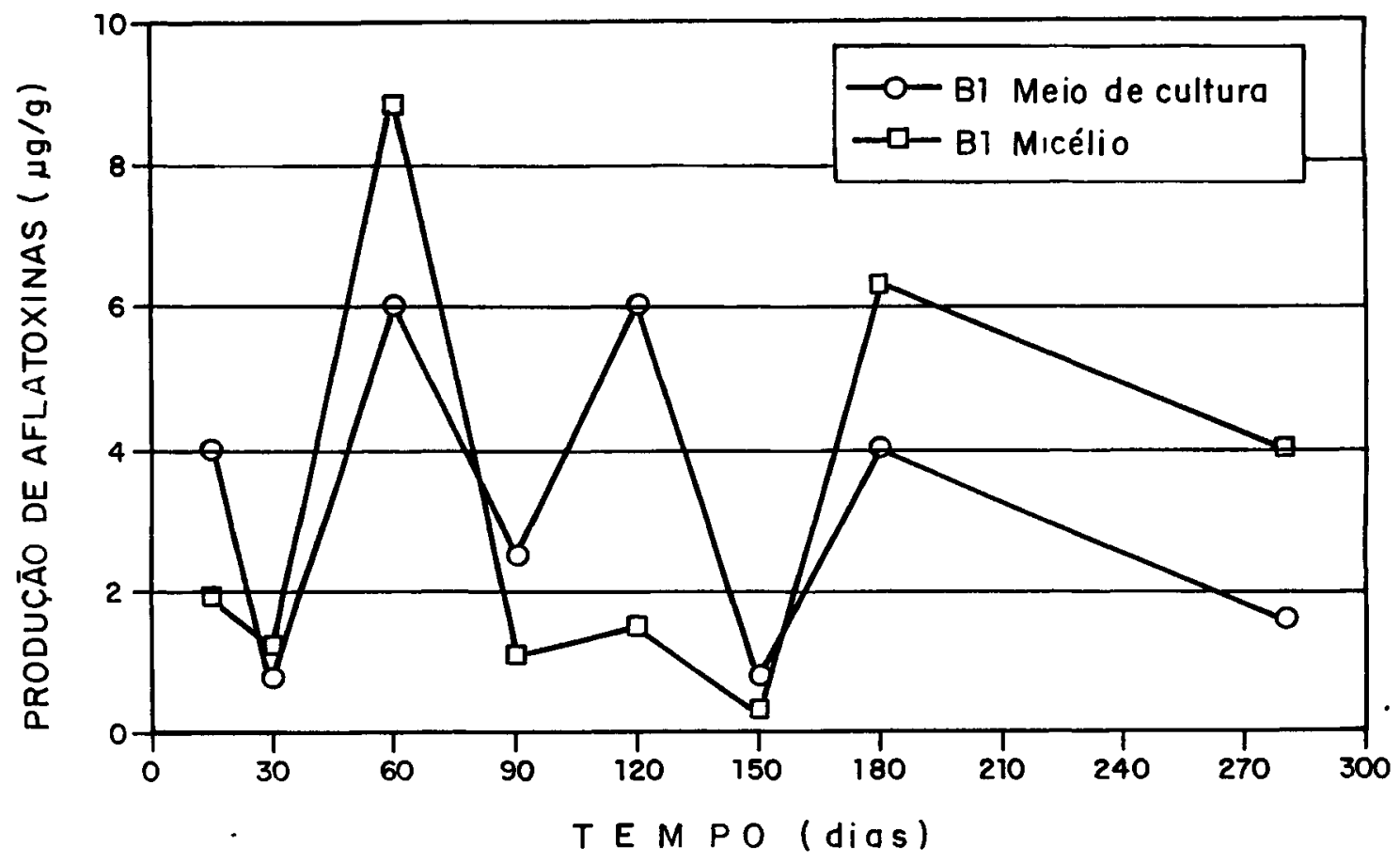

Figura 1 - Produção de aflatoxinas no meio de cultura e no micélio, da linhagem 2, mantida sob óleo mineral 


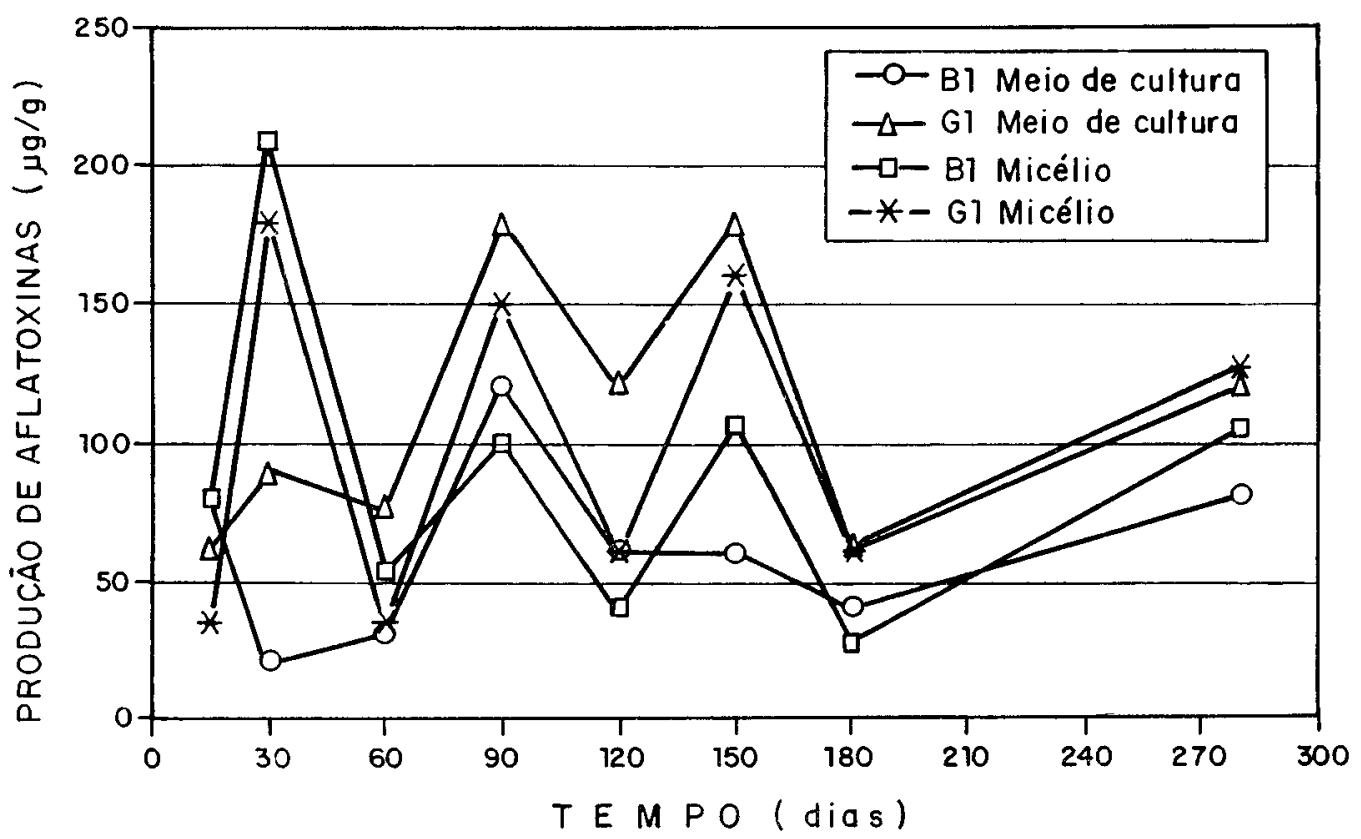

Figura 2 - Produção de aflatoxinas no meio de cultura e no micélio, da linhagem 4, mantida sob óleo mineral

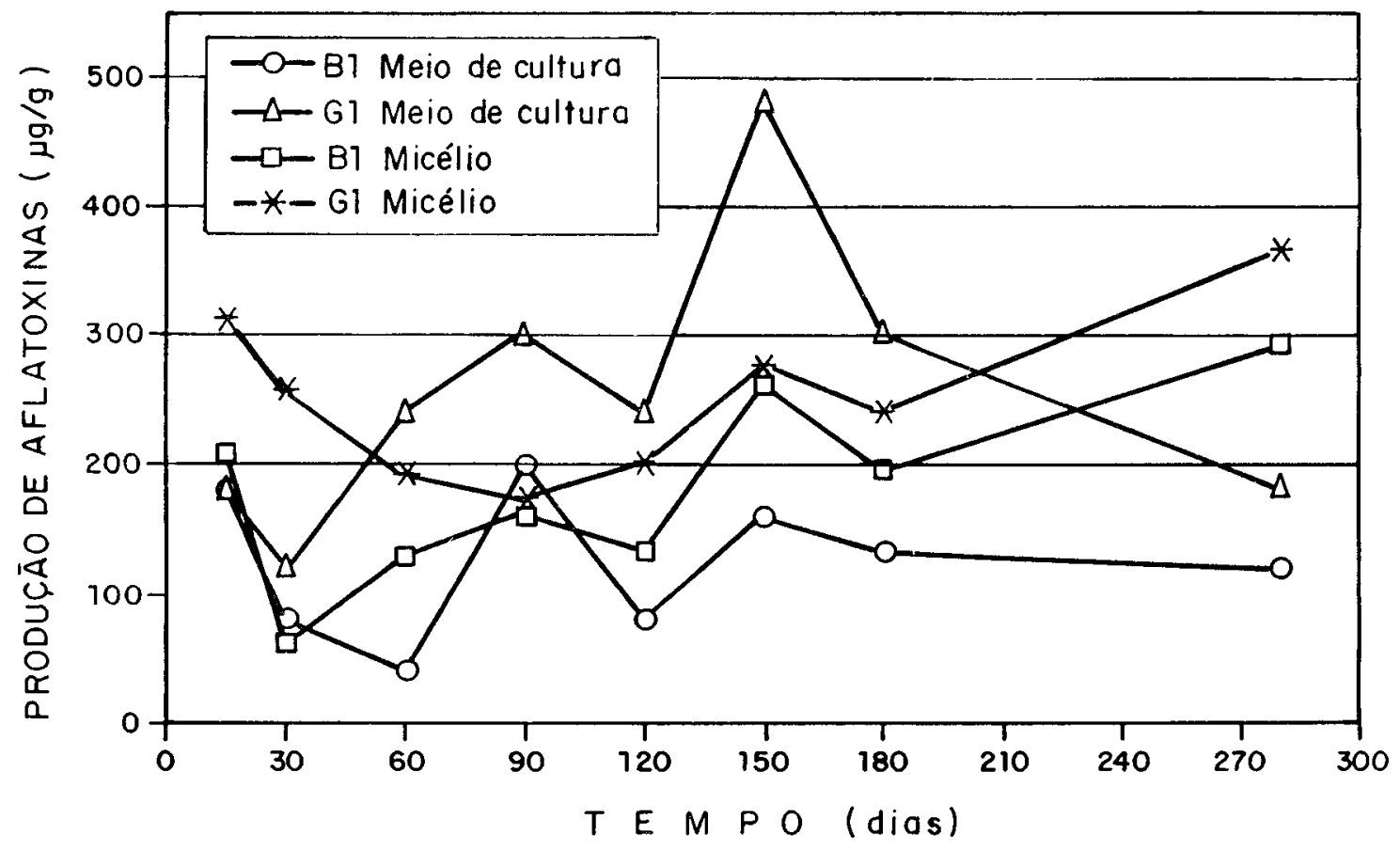

Figura 3 - Produção de aflatoxinas no meio de cultura e no micélio, da linhagem 6, mantida sob óleo mineral 


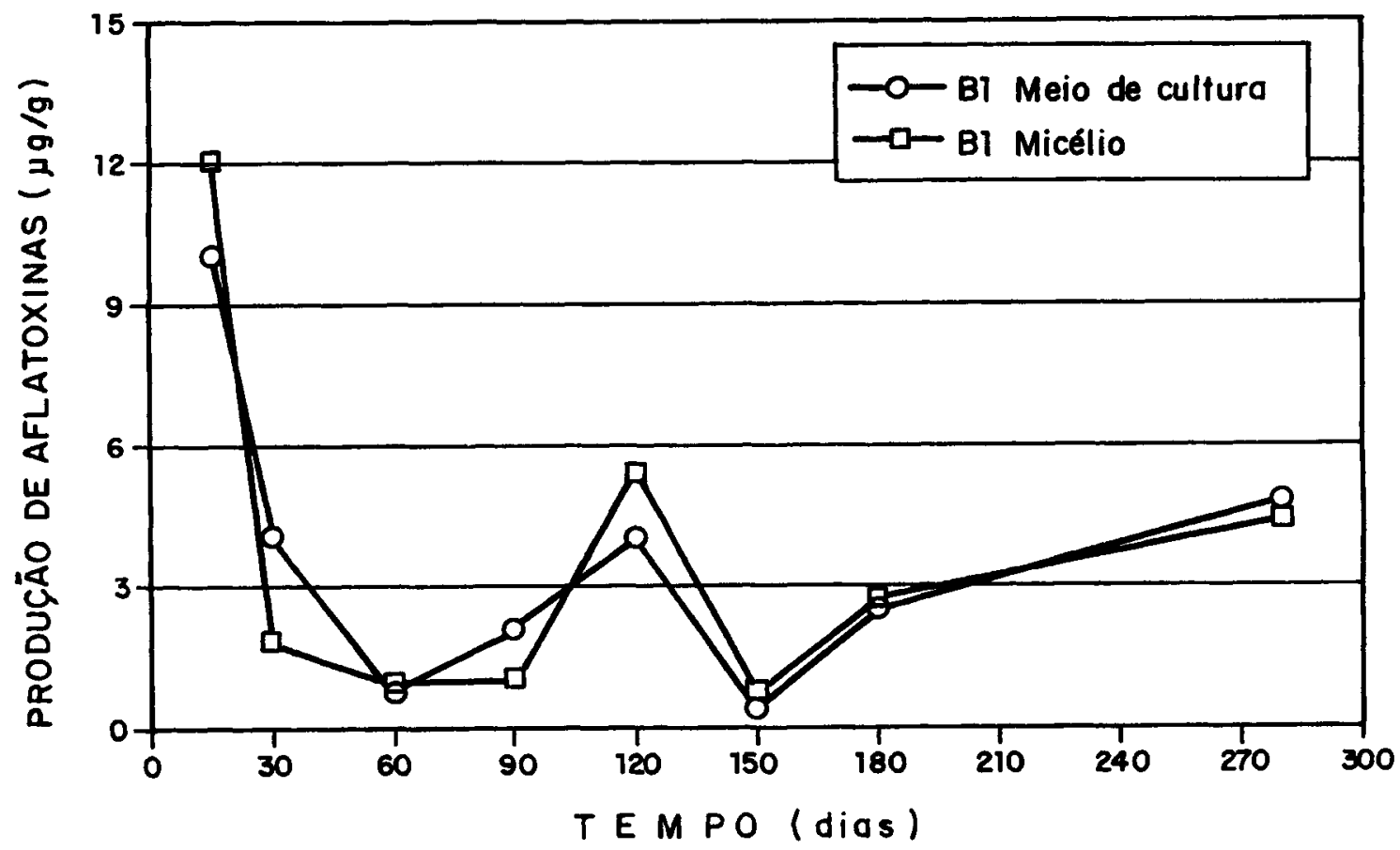

Figura 4 - Produção de aflatoxinas no meio de cultura e no micélio, da linhagem 2, repicada periodicamente.

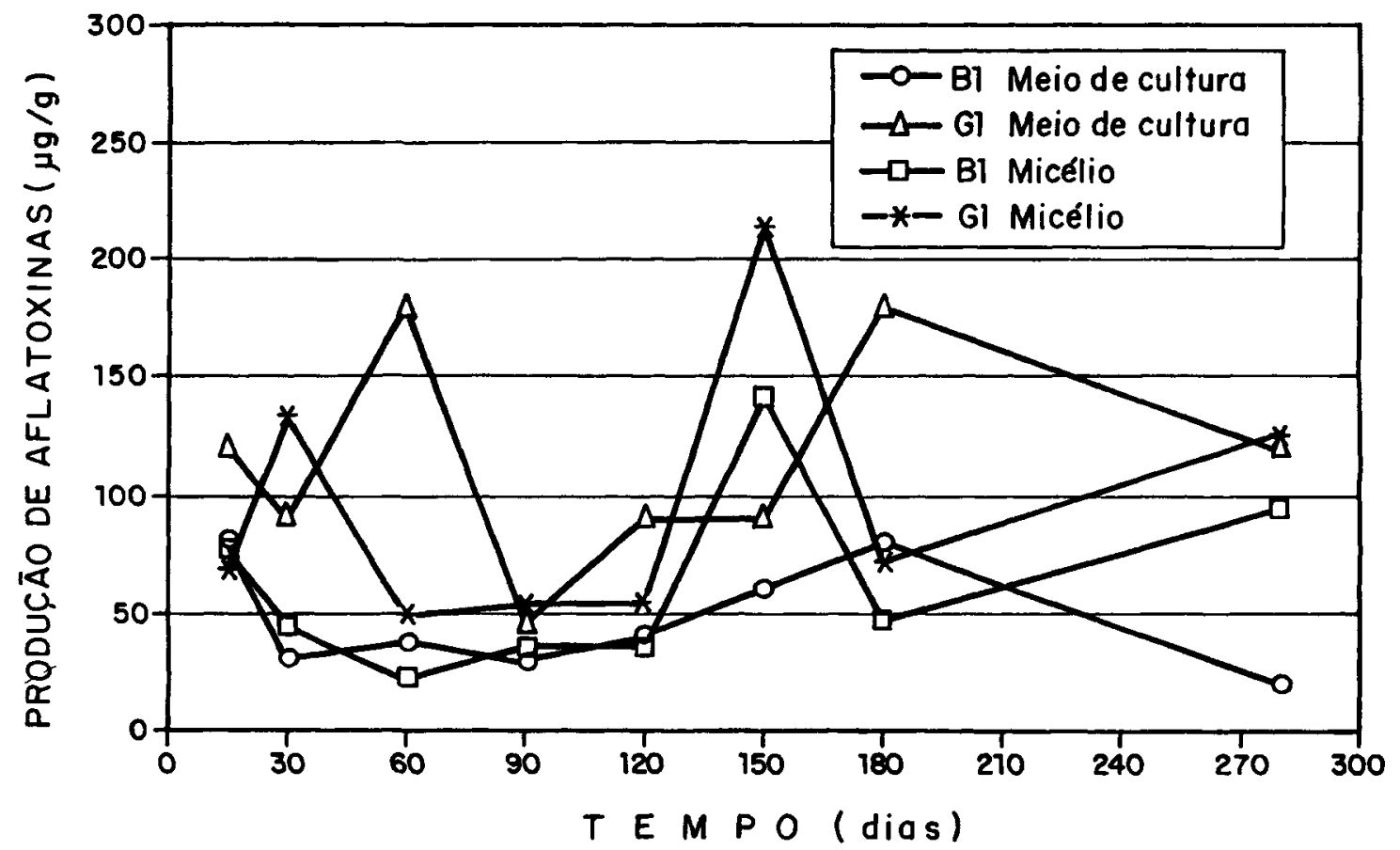

Figura 5 - Produção de aflatoxinas no meio de cultura e no micélio, da linhagem 4, repicada periodicamente. 
TABELA 2 - Produção de aflatoxinas pelas linhagens 2, 4 e 6, mantidas sob óleo mineral, em diferentes tempos de manutenção (Média de duas repetições).

\begin{tabular}{|c|c|c|c|c|c|}
\hline \multirow{3}{*}{$\begin{array}{c}\text { Tempo de } \\
\text { Estocagem } \\
\text { (dias) }\end{array}$} & \multirow{3}{*}{ Linhagem } & \multicolumn{4}{|c|}{ Produção de Aflatoxinas } \\
\hline & & \multicolumn{2}{|c|}{ Meio de Cultura $(\mu \mathrm{g} / \mathrm{l})$} & \multicolumn{2}{|c|}{ Micélio $(\mu \mathrm{g} / \mathrm{kg})$} \\
\hline & & $B_{1}$ & $\mathrm{G}_{1}$ & $B_{1}$ & $G_{1}$ \\
\hline \multirow{3}{*}{15} & 2 & 4,0 & ND & 1,9 & ND \\
\hline & 4 & 80,0 & 60,0 & 8,0 & 35,0 \\
\hline & 6 & 180,0 & 180,0 & 209,0 & 313,0 \\
\hline \multirow{3}{*}{30} & 2 & 0,8 & ND & 1,2 & ND \\
\hline & 4 & 20,0 & 90,0 & 209,5 & 180,0 \\
\hline & 6 & 80,0 & 120,0 & 61,0 & 257,0 \\
\hline \multirow{3}{*}{60} & 2 & 60,0 & ND & 8,8 & ND \\
\hline & 4 & 30,0 & 75,0 & 53,0 & 35,3 \\
\hline & 6 & 40,0 & 240,0 & 129,0 & 193,0 \\
\hline \multirow{3}{*}{90} & 2 & 2,5 & ND & 1,1 & ND \\
\hline & 4 & 120,0 & 180,0 & 100,0 & 150,0 \\
\hline & 6 & 200,0 & 300,0 & 161,0 & 173,0 \\
\hline \multirow{3}{*}{120} & 2 & 6,0 & ND & 1,5 & ND \\
\hline & 4 & 60,0 & 120,0 & 40,0 & 60,0 \\
\hline & 6 & 80,0 & 240,0 & 133,0 & 200,0 \\
\hline \multirow{3}{*}{150} & 2 & 0,8 & ND & 0,3 & ND \\
\hline & 4 & 60,0 & 180,0 & 106,0 & 160,0 \\
\hline & 6 & 160,0 & 480,0 & 261,0 & 277,0 \\
\hline \multirow{3}{*}{180} & 2 & 4,0 & ND & 6,3 & ND \\
\hline & 4 & 40,0 & 60,0 & 27,3 & 61,4 \\
\hline & 6 & 133,0 & 300,0 & 196,0 & 240,0 \\
\hline \multirow{3}{*}{280} & 2 & 1,6 & ND & 4,0 & ND \\
\hline & 4 & 80,0 & 120,0 & 104,0 & 126,2 \\
\hline & 6 & 120,0 & 180,0 & 291,0 & 364,0 \\
\hline
\end{tabular}

ND $=$ Não detectada. 
TABELA 3 - Produção de aflatoxinas pelas linhagens 2, 4 e 6 repicadas periodicamente (Média de duas repetições).

\begin{tabular}{|c|c|c|c|c|c|}
\hline \multirow{3}{*}{$\begin{array}{l}\text { Tempo } \\
\text { (dias) }\end{array}$} & \multirow{3}{*}{ Linhagem } & \multicolumn{4}{|c|}{ Produção de Aflatoxinas } \\
\hline & & \multicolumn{2}{|c|}{ Meio de Cultura $(\mu \mathrm{g} / \mathrm{l})$} & \multicolumn{2}{|c|}{ Micélio $(\mu \mathrm{g} / \mathrm{kg})$} \\
\hline & & $B_{1}$ & $\mathrm{G}_{1}$ & $\mathrm{~B}_{1}$ & $G_{1}$ \\
\hline \multirow{3}{*}{15} & 2 & 10,0 & ND & 12,0 & ND \\
\hline & 4 & 80,0 & 60,0 & 77,5 & 68,0 \\
\hline & 6 & 70,0 & 105,0 & 120,0 & 193,0 \\
\hline \multirow{3}{*}{30} & 2 & 4,0 & ND & 1,8 & ND \\
\hline & 4 & 30,0 & 90,0 & 44,0 & 133,0 \\
\hline & 6 & 140,0 & 210,0 & 177,0 & 266,0 \\
\hline \multirow{3}{*}{60} & 2 & 0,8 & ND & 0,95 & ND \\
\hline & 4 & 80,0 & 180,0 & 21,7 & 49,0 \\
\hline & 6 & 80,0 & 240,0 & 212,0 & 318,0 \\
\hline \multirow{3}{*}{90} & 2 & 2,1 & ND & 1,0 & ND \\
\hline & 4 & 30,0 & 45,0 & 35,5 & 53,3 \\
\hline & 6 & 80,0 & 80,0 & 152,0 & 163,0 \\
\hline \multirow{3}{*}{120} & 2 & 4,0 & ND & 5,4 & ND \\
\hline & 4 & 40,0 & 90,0 & 36,0 & 54,0 \\
\hline & 6 & 80,0 & 157,0 & 111,0 & 166,0 \\
\hline \multirow{3}{*}{150} & 2 & 0,4 & ND & 0,8 & ND \\
\hline & 4 & 60,0 & 90,0 & 142,0 & 214,0 \\
\hline & 6 & 120,0 & 180,0 & 183,0 & 235,0 \\
\hline \multirow{3}{*}{180} & 2 & 2,5 & ND & 2,7 & ND \\
\hline & 4 & 80,0 & 180,0 & 47,5 & 71,5 \\
\hline & 6 & 80,0 & 120,0 & 54,0 & 81,0 \\
\hline \multirow{3}{*}{280} & 2 & 4,8 & ND & 4,4 & ND \\
\hline & 4 & 20,0 & 120,0 & 94,7 & 126,0 \\
\hline & 6 & 30,0 & 90,0 & 30,7 & 46,2 \\
\hline
\end{tabular}

ND $=$ Não detectada. 


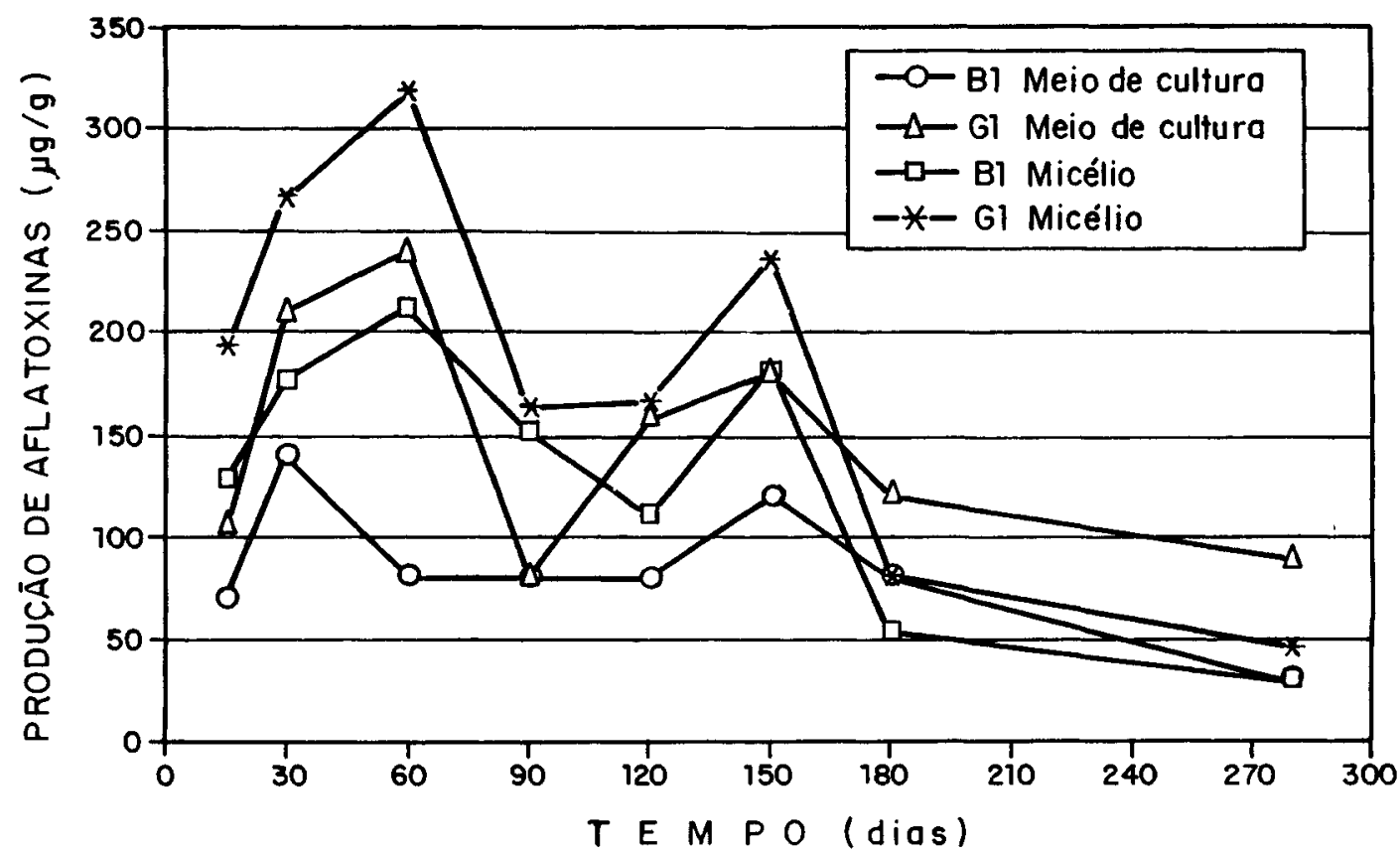

Figura 6 - Produção de aflatoxinas no meio de cultura e no micélio, da linhagem 6, repicada periodicamente.

proporcional ao nível de inóculo inicial, além da temperatura de incubação.

$\mathrm{Na}$ natureza ocorre uma interação microbiológica, onde a produção de toxina dá uma certa vantagem seletiva ao organismo produtor. Enquanto quase todas as linhagens de $A$. parasiticus são toxigênicas, em $A$. flavus nem todas produzem aflatoxinas. Em ambas as espécies a produção está relacionada às condições ambientais e, segundo SCHROEDER; ASHWORTH (1966), a produção de aflatoxinas é o resultado da interação do genótipo de uma linhagem e o ambiente em que está crescendo.

O meio de Czapeck, utilizado no presente estudo, é pobre $\mathrm{cm}$ nutrientes; sendo assim, o fungo necessita sintetizar substâncias mais complexas, a partir de fontes simples. Provavelmente, o fungo cultivado em meios sintéticos ricos perde sua capacidade de produzir aflatoxinas com maior facilidade que o fungo cultivado em meios mais pobres, uma vez que naquele meio o fungo encontra a substância pronta sem precisar seguir algumas vias metabólicas para a sua sintese. Desta forma, um estudo comparativo do comportamento do fungo toxigênico num meio sintético rico, com um meio sintético pobre, além de um substrato natural, poderia esclarecer estas suposições.

Por outro lado, a técnica de liofilização para preservação de fungos toxigênicos tem se mostrado mais eficiente. WEI; JONG (1986), testando as linhagens toxigênicas do $A$. flavus, mantidas na coleção da American Type Culture Collection (ATCC), verificaram que todas as linhagens mantiveram as suas características de produção de aflatoxinas originais, após longo período de manutenção.

\section{REFERÊNCIAS BIBLIOGRÁFICAS}

ABOU-GABAL, M.; FAGERLAND, J. Ultrastructure of the chlamydospore growth phase of Aspergillus parasiticus associated with higher production of aflatoxins. Mykosen, Berlin, v.24, p.307-311, 1981.

BHATNAGAR, R.K.; AHMAD, D.; MUKERJI.K.G.; VENKITASUBRAMANIAN, T.A. Role of blastospores in protecting Aspergillus parasiticus NRRL 3240 from high levels of aflatoxins. Applied and Environmental Microbiology, Baltimore, v.44, p.579-582, 1982. 
BUTLER, W.H. Aflatoxin. In: PURCHASE, I.F.H., ed. Micotoxins. Amsterdam : Elsevier, 1974. p.1-28.

CHRISTENSEN, C.M. Molds, mushrooms and mycotoxins. Minneapolis. University of Minnesota Press, 1975. 265p.

COOMES, T.J.; FEUELL, A.J. Recommended procedures for the detection and estimation of aflatoxins $B_{1}$ in groundnuts and groundnuts materials. London: Tropical Products Institute, 1965, 24p. (Report G 13).

DAVIS, N.D.; DIENER, U.L.; ELDRIDGE, D.W. Production of aflatoxins $B_{1}$ and $G_{1}$ by Aspergillus flavus in semisynthetic medium. Applied Microbiology, Baltimore, v.14, p.378-380, 1966.

DIENER, U.L.; DAVIS, N.D. Aflatoxin formation by Aspergillus flavus. In: GOLDBLATT, L.A., ed. Aflatoxin. New York : Academic Press. 1969. p.1354.

FENNELL, D.I. Conservation of fungous culture. Botanical Reviews, New York, v.26, p.79-141, 1960.

FONSECA, H,; MARTINELLI FILHO, A.; DEL NERY, H.; RONCATO, E. Espécies de Aspergillus produtoras de aflatoxinas na regiāo Araraquarense, SP. Anais da Escola Superior de Agricultura "Luiz de Queiroz", Piracicaba, v.31, p.519-536, 1974.

HESSELTINE, C.W.; SHOTWELL, O.L.; ELLIS, J.J.; STUBBLEFIELD, R.D. Allatoxin formation by Aspergillus flavus. Bacteriological Reviews, Washington, v.30, p.795-805, 1966.

KARUNARATNE, A.; BULLERMAN, L.B. Interactive effects of spore load and temperature on aflatoxin production. Journal of Food Protection, Orange, NJ, v.53, p.227-229, 1990 .

LEAICH, L.L.; PAPA, K.E. Aflatoxins in mutants of Aspergillus favis. Mycopathologya et Mycologya Applicata, Dordrecht, v.52, p.223-229, 1974.

LIN, M.T. Biologia dos fungos toxigênicos. IN: ENCONTRO NACIONAL DE MICOTOXINAS: PROBLEMAS E SOLUÇÕES. 1980. São Paulo. Anais... São Paulo : SBM, 1980. p.11-22, 1982.

MOREAU, C. Moulds, Toxins \& Food. Chichester: John Wiley, 1979. 477p.
MURAKAMY, H.; OUWAKI, K.; TAKASE, S. Aflatoxin strain, ATCC 15517. Journal of General and Applied Microbiology, Tokyo, v.12, p.195-206, 1966.

MURAKAMY, H.; SAGAWA, H.; TAKASE, S. Nonproductivity of aflatoxin by japanese industrial strains of the Aspergillus. III. Common characteristes of the aflatoxin-producing strains. Joumal of General and Applied Microbiology, Tokyo, v.14, p.251-262, 1968.

RAPER, K.B.; FENNELL, D.I. The genus Aspergillus. Baltimore. Williams \& Wilkins. 1965. 686p.

SCHROEDER, H.W.; ASWORTH, L.J. Aflatoxins: some factors affecting production and location of toxins Aspergillus flavus - oryzae. Journal of Stored Products Research, New York, v.1, p.267-271, 1966.

SCOTT, P.M.; LAWRENCE, G.W.; van WALBEEK, W. Detection of mycotoxins by thin-layer chromatography: application to screening of fungal extracts. Applied Microbiology, Baltimore, v.20, p.839-842, 1970 .

TORRES, J,; GUARRO, J. SUAREZ, G.; SUNE, N. CALVO, M.A.; RAMIREZ, C. Morphological changes in strains of Aspergillus flavus Link ex Fries and Aspergillus parasiticus Speare related with aflotoxin production. Mycopathologia, Dordrecht, v.72, p.171-174, 1980 .

WEI, D.L.; JONG, S.C. Production of aflatoxins by strains of the Aspergillus flavus group maintained in ATCC. Mycopathologia, Dordrecht, v.93, p.19-24, 1968.

WICKLOW, D.T.; SHOTWELL, O.L. Intrafungal distribution of a flatoxin among conidia and sclerotia of Aspergillus flavus and Aspergillus parasiticus. Canadian Journal of Microbiology, Ottawa, v.29, p.1-5, 1982 .

WOGAN, G.N. Chemical nature and biological effects of the aflatoxins. Bacteriological Reviews, Baltimore, v.30, p.460-470, 1966.

Trabalho entregue para publicação em 19.02 .92 Trabalho aprovado para publicação em 08.06.92 